\title{
Evaluasi Penerapan Chemical Handling di Area Produksi Sebagai Upaya Pencegahan Kecelakaan Kerja di PT Pupuk Kalimantan Timur
}

\author{
Implementation Evaluation of Chemical Handling in Production Area as Prevention of Work \\ Accidents in PT Pupuk Kalimantan Timur
}

\author{
Rizka Khawari Aulia ${ }^{1}$, Meirina Ernawati ${ }^{2}$ \\ ${ }^{1,2}$ Program Studi Kesehatan Masyarakat, FKM Universitas Airlangga \\ email: rizka.khawari.aulia-2014@fkm.unair.ac.id
}

\begin{abstract}
Abstrak
Chemical handing merupakan langkah upaya pencegahan terhadap bahaya yang ditimbulkan dari zat kimia. Industri petrokimia sebagai industri yang bergerak dalam pengolahan bahan kimia sangat diperlukan upaya pencegahan tersebut, maka kesesuaian setiap langah dalam prosedur perlu diterapkan agar proses produksi berjalan dengan aman dan terhindar dari kecelakaan kerja. Tujuan penelitian ini adalah untuk mengetahui kelengkapan dan kesesuaian penerapan chemical handling yang dilakukan di PT Pupuk Kaltim dengan kesesuaian peraturan yang berlaku. Jenis penelitian ini adalah penelitian observasi deskriptif. Populasi penelitian adalah operatir di setiap unit area produksi yang meliputi unit amoniak, urea dan utility. Sumber data diperoleh dari pengamatan di lapangan dan wawancara langsung kepada operator yang bertugas. Variabel yang diteliti adalah dari karakteristik bahan kimia yang digunakan di area produksi, aspek pictogram Globally Harmonized Sistem (GHS), kompatibilitas bahan kimia, tata letak penyimpanan bahan kimia. Hasil dari penerapan chemical handling telah berjalan dengan baik, namun dalam tahapan penyimpanan tata letak bahan kimia masih ditemukan bahan kimia yang seharusnya tidak boleh dilakukan penyimpanan di satu tempat yang sama. Saran untuk PT Pupuk Kaltim perlu dilakukan pembuatan tabel kompatibilitas bahan kimia beserta langkah antisipasinya dan ditempel di setiap chemical shelter atau tempat penyimpanan bahan kimia sebagai informasi sifat bahan kimia yang disimpan di tempat tersebut, agar para operator yang bekerja dapat mengetahui penanganan yang sesuai dengan bahan kimia tersebut.
\end{abstract}

Kata Kunci: chemical handling, Globally Harmonized System

\section{Abstract}

Chemical handling is a precautionary measure against the danger posed by chemicals. Petrochemical industri as an industri engaged in the processing of chemical is very necessary prevention effort, the appropriate in every step in the procedure should be applied for the production process runs safety and avoid work accident. The purpose of this study is to determine the completeness and appropriateness of the application of chemical handling conducted at PT Pupuk Kaltim with compliance with applicable regulations. The type of this research is descriptive observation research. The study population is operator in every unit of production area including ammonia unit, urea and utility. Sources of data were obtained from field observations and direct interviews to operators on duty. The variables studied were from the chemical characteristics used in the production area, the pictogram aspects of Globally Harmonized Sistem (GHS), chemical compatibility, chemical storage layout. The result of the application of chemical handling has been running well, but in the storage stage of chemical layout is still found chemicals that should not be stored in one place the same. Suggestion for PT Pupuk Kaltim needs to make table of chemical compatibility along with anticipation step and affixed in every chemical shelter or chemical storage place as information of chemical properties stored in that place, so that operators who work can know handling according to chemicals.

Keyword: chemical handling, Globally Harmonized System

\section{Pendahuluan}

Keselamatan dan Kesehatan Kerja (K3) dalam industri petrokimia merupakan permasalahn yang harus mendapatkan perhatian. Berbagai permasalahan pada industri yang berbasis bahan kimia ini banyak terjadi. Bahaya atau hazard seperti yang diketahui tergolong kedalam beberapa macam diantarnya bahaya fisik, kimia, biologi, psikologi, ataupun ergonomi. Chemical hazard atau bahaya yang berasal dari bahan kimia mampu menimbulkan risiko baik bagi kesehatan manusia maupun keselamatan. Sehingga perlu dilakukan penanganan secara khusus untuk mengendalikan bahaya yang diakibatkan dari bahan kimia. Penggunaan bahan kimia disatu pihak digunakan untuk mendukung dalam pemenuhan kebutuhan manusia, namun disisi lain bahan kimia sangat 
memberi dampak yang berbahaya bagi keselamatan dan kesehatan pekerja serta kelestarian lingkungan ${ }^{1}$.

Chemical handling merupakan upaya pencegahan yang dilakukan untuk mengendalikan bahaya yang ditimbulkan dari faktor kimia. Upaya tersebut salah satu nya adalah sistem klasifikasi pada masing-masing bahaya bahan kimia. Bahaya bahan kimia seperti yang diketahui dapat masuk kedalam tubuh melalui saluran pernafasan, saluran pencernaan, kulit dan mukosa. Baik dalam bentuk zat padatan, cair, gas, uap maupun partikel. Efek yang kemungkinan terjadi adalah iritasi, alergi, korosif, asphyxia, keracunan sistemik, kanker, kerusakan/kelainan janin, pneumoconiosis, efek bius (narkose) dan lain sebagainya. Sehingga untuk mengurangi bahaya-bahaya kesehatan maupun keselamatan perlu dilakukan penanganan bahan kimia secara tepat dan sesuai ${ }^{3}$.

Chemical handling penting dan harus dilakukan klasifikasi pada masing-masing bahan kimia pada perusahaan petrokimia, agar tidak menimbulkan masalah. Klasifikasi tersebut diantaranya berguna seperti untuk memudahkan penglolaan meliputi penanganan dan penyimpanan serta pengawasan bahan kimia, memenuhi hak konsumen untuk mengetahui informasi (right to know chemicals), sebagai langkah preventif awal paling esensial dalam rangka pengurangan risiko. Apabila tidak dilakukan langkah seperti itu maka masalah akan timbul seperti kasuskasus yang terjadi akibat sistem pengelolaan bahan kimia yang salah misalnya kasus tragedi Bhopal, dimana sekitar lebih dari 18.000 orang meninggal akibat bahan kimia yang sangat beracun terlepas ke udara. Bahan kimia beracun tersebut adalah metil isosianat (MIC) di kota Bhopal di India pada tahun $1984^{2}$.

Organisasi internasional WHO (1994) dalam Masita (2013) terdapat sekitar 150.000 bahan kimia yang telah beredar di seluruh dunia. Dan semakin tahun terus bertambah sekitar 200 hingga 1.000 jenis bahan kimia baru yang tergunakan. Diataranya banyak jenis bahan kimia tersebut sekitar 12.000 diantarnya telah dipastikan memiliki dampak yang berbahaya terhadap kesehatan manusia. Data lain juga menyebutkan jenis dan jumlah bahan kimia yang dipakai industri seperti di US sekitar 650.000 macam. Beberapa bahan kimia yang telah diperdagangkan telah ada sekitar 63.000 jenis, 50.000 jenis diantaranya biasanya digunakan dalam kehidupan seharihari, 1.500 jenis diataranya merupakan bahan aktif pestisida, sekitar 4.000 jenis sebagai bahan aktif obat-obatan, dan 2.500 jenis digunakan sebagai bahan tambahan makanan. Dari sekian banyak jenis dan sifat bahan kimia tersebut hanya beberapa yang telah berhasil di evaluasi mengenai dampak terhadap kesehatan ataupun pada lingkungan ${ }^{4}$.

PT Pupuk Kaltim merupakan industri petrokimia sebagai salah satu anak perusahaan dari PT Pupuk Indonesia (Persero) yang lahir untuk memnuhi kebutuhan pupuk di bidang pertanian di Indoneisa. PT Pupuk Kaltim sebagai perusahaan penghasil terbesar urea dan amoniak di Indonesia dengan kapasitas hingga 3,43juta ton untuk jenis urea. Selama melakukan proses produksi PT Pupuk Kaltim tidak terlepas dari penggunaan banyak jenis bahan kimia. Bahan-bahan kimia tersebut dapat berupa suatu produk akhir atau bagian bentuk bahan baku yang digunakan untuk menunjang hasil produksinya. Saat ini PT Pupuk Kaltim mengoperasikan 7 unit pabrik yaitu Pabrik-1A, Pabrik-2, Pabrik-3, Pabrik-4, Pabrik-5, Pabrik-6 (Boiler Batubara) dan Pabrik-7 (NPK). PT Pupuk Kaltim menjalankan operasi bisnisnya dengan tujuan untuk memenuhi kebutuhan pupuk domestik, baik untuk sektor tanaman pangan maupun untuk sektor tanaman perkebunan guna mendukung ketahanan pangan nasional Banyaknya pabrik yang beroperasi di PT Pupuk Kaltim dan bahan kimia sebagai bahan utamanya, maka perlindungan sangat 
diperlukan tidak hanya terhadap tenaga kerja namun juga keselamatan dan kesehatan di sekitar area pabrik ${ }^{5}$.

Tujuan umum dari penelitian ini adalah untuk mengetahui nama-nama bahan kimia yang terdapat di PT Pupuk Kaltim, kemudian diklasifikasikan bahan kimia tersebut, dan langkah penanganan bahan kimia atau chemical handling yang tepat yang harus dilakukan di PT Pupuk Kaltim yang disesuaikan pada Peraturan Menteri Industri Nomor 23 tahun 2013 tentang Perubahan Sistem Harmonisasi Global Klasifikasi Dan Label Pada Bahan Kimia.

\section{Metode}

Penelitian ini menggunakan metode penelitian observasional karena peneliti hanya melakukan pengamatan tanpa memberikan itervensi pada variabel yang akan diteliti. Berdasarkan waktu, penelitian ini merupakan cross sectional karena hanya dilakukan pada satu kali saja dan faktor risiko maupun dampak dilihat dan diukur menurut keadaan pada saat melakukan observasi. Rancangan penelitian menggunakan penelitian deskriptif. Variabel dalam penelitian ini yaitu karakteristik bahan kimia yang digunakan di area produksi, aspek pictogram GHS, kompatibilitas bahan kimia, dan tata letak penyimpanan bahan kimia. Lokasi penelitian adalah di PT Pupuk Kalimantan Timur, Bontang, Kaltim. Waktu pengambilan data dilakukan pada bulan Januari hingga Maret 2018. Metode yang digunakan dalam pengumpulan data adalah data primer dengan cara observasi dan wawancara secara langsung ke setiap bagian unit proses produksi untuk mengetahui secara detail tentang penerapan chemical handling. Data sekunder berupa logbook daftar bahan kimia, profil perusahaan, dan referensi literature yang memiliki informasi relevan terkait chemical handling yang ada di perusahaan.
Setelah hasil data observasi dan pengumpulan data sekunder diperoleh, kemudian data diolah dan disajikan menggunakan tabel dan narasi. Kemudian di analisis secara deskriptif, yaitu dengan menilai dan membandingkan untuk chemical handling di tempat kerja dengan mengacu pada standart peraturan perundang-undangnan terkait. Dari sini peneliti akan mengetahui tekait penerapan dari penanganan bahan kimia atau chemical handling di PT Pupuk Kaltim yang kemudian akan diberikan saran dan masukan sebagai langkah perbaikan dan upaya untuk mencegah terjadinya kecelakaan kerja

\section{Hasil}

\section{Gambaran Proses Produksi}

Pada proses produksi amoniak di PT Pupuk Kaltim secara garis besar tahapa tersebut diantaranya: 1) gas alam yang diperoleh dihilangkan kandungan sulfur nya terlebih dahulu. 2) gas yang sudah bebas sulfur tersebut dicampur dengan uap air dan dipanaskan lagi yang kemudian direaksikan, hasil reaksi berupa gas hydrogen $\left(\mathrm{H}_{2}\right)$, karbon monoksida $\left(\mathrm{CO}_{2}\right)$ dan karbon monoksida (CO). 3) tahapan berikutnya gas hasil reaksi tersebut direaksikan dengan udara maka dihasilkan has hidrogen $\left(\mathrm{H}_{2}\right)$, nitrogen $\left(\mathrm{N}_{2}\right)$, karbon monoksida $\left(\mathrm{CO}_{2}\right)$ dan karbon monoksida (CO). 4) gas-gas tersebut direaksikan pada shift converter untuk mengubah gas karbon monoksida menjadi karbon dioksida dan nitrogen. 5) gas karbon dioksida dipisahkan dari gas nitrogen dan hidrogen pada unit $\mathrm{CO}_{2}$ removal. Gas karbon dioksida yang sudah terpisah dikirim ke pabrik urea untuk bahan bau urea. 6) gas nitrogen dan hidrogen yang disebut sebagai gas sintesa, dimurnikan dari gas sisa-sisa gas karbon dioksida dan gas karbon monoksida pada reactor methanator. 7) kemudian gas hidrogen dan nitrogen direaksikan di dalam coverter amoniak di dinginkan hingga menjadi amoniak 
cair. 8) sebagian amoniak cair dikirim ke urea untuk di proses menjadi urea, sedangkan sebagian lagi disimpan dalam tangka penyimpanan amoniak sebelum dikapalkan.

\section{Bahaya Kimia Pada Proses Di Area Produksi}

Risiko bahaya kimia selama proses berjalan produksi dapat menyebabkan gangguan baik secara fisik maupun kesehatan pekerja, karena yang diketahui masih terdapat beberapa bagian dari proses produksi yang masih dilakukan secara manual oleh tenaga kerja, misalnya pada proses loading atau penambahan barang ke sebuah wadah chemical storage, sehingga jika tidak mendapatkan pengawasan secara teliti berpeluang terjadi nya kecelakaan kerja. Sifat bahan kimia yang sebagian besar merupakan zat toksik dimana sangat iritan dan korosif yang mampu menimbulkan efek paling parah yaitu berupa kanker. Sehingga perlu dilakukan langkah berupa penerapan chemical handling.

\section{Landasan Hukum Terkait Chemical handling}

Peraturan Menteri Industri Nomor 23 tahun 2013 tentang Perubahan Sistem Harmonisasi Global Klasifikasi dan Label pada Bahan Kimia secara jelas telah mengatur terkait penanganan wajib terhadap bahan kimia yang harus dilakukan pengusaha kedalam beberapa kriteria, diantaranya untuk kategori klasifikasi bahan kimia, disini dijelaskan bahwa klasifikasi bahan kimia harus sudah tergolongkan kedalam bahan kimia dengan sifat bahaya yang menimbulkan bahaya secara fisik, bahaya terhadap kesehatan, dan bahaya terhadap lingkungan akuatik atau lingkungan perairan. Selain itu kategori berikutnya adalah mengenai keterangan yang ada pada MSDS (Material Safety Data Sheet) atau LDKB (Lembar Data Keselamatan Bahan), disini keterangan untuk wajib GHS telah digolongkan kedalam 16 poin yang harus dimuat dalam buku informasi MSDS perusahaan yang menggunakan bahan kimia. Selanjutnya kategori untuk klasifikasi pictogram yaitu simbol-simbol penanda bahaya pada produk bahan kimia, klasifikasi pictogram tersebut telah jelas terbagi kedalam 13 kriteria sifat bahan kimia, selanjutnya untuk sistem dan tata cara pelabelan bahan kimia, pengkajian ulang bahan kimia, kewajiban pelaku usaha yang memproduksi bahan kimia dan/atau produk konsumen.

\section{Klasifikasi Bahan Kimia Di Area Produksi}

Pada proses observasi yang dilakukan, peneliti melakukan pengumpulan data untuk nama-nama bahan kimia apa saja yang digunakan sepanjang proses produksi, untuk kemudian dapat dilakukan analisis mengenai langkah apa yang harus dilakukan untuk menangani bahan kimia tersebut. Klasifikasi pada bagian ini merupakan klasifikasi bahan kimia berdasarkan wujud bahan kimia, bahaya bahan kimia, dan sifat bahan kimia. Namanama bahan kimia tersebut telah terkumpul sebanyak 33 jenis bahan kimia. Zat kimia tersebut bai zat kimia tunggal maupun campuran. Setelah dilakukan analisis didapatkan hasil sebagai berikut :

Tabel 1. Ketercapaian Klasifikasi Bahan Kimia di Area Produksi PT Pupuk Kaltim

\begin{tabular}{lc}
\hline $\begin{array}{l}\text { Klasifikasi Bahan } \\
\text { Kimia }\end{array}$ & Ketercapaian \\
\hline Berdasaran Wujud & $100 \%$ \\
\hline Berdasarkan Bahaya & $100 \%$ \\
\hline Berdasarkan Sifat & $87 \%$ \\
\hline
\end{tabular}

Sumber Data Primer

Berdasarkan tabel 1 dapat dilihat bahwa ketercapian kesesuaian antara nama bahan kimia yang digunakan di PT Pupuk Kaltim dengan klasifikasi berdasarkan Permen Industri Nomor 23 tahun 2013 untuk kategori klasifikasi bahan kimia berdasarkan wujud telah terklasifikasi seluruhnya, berdasarkan 
bahaya juga telah terklasifikasi seluruhnya, namun untuk klasifikasi berdasarkan sifat masih terdapat nama-nama bahan kimia yang tidak dietahui sifat nya secara jelas, hal tersebut dikarenakan bahan kimia tersebut merupakan bahan kimia campuran, sehingga MSDS yang digunakan juga menggunakan kombinasi dari dua supplier yang berbeda.

\section{Pictogram GHS (Globally Harmonized Sistem)}

Sebagai upaya dalam melindungi tenaga kerja yang melakukan interaksi langsung dengan bahan kimia, maka PT Pupuk Kaltim menerapkan pemberian informasi pada masing-masing tempat penyimpanan bahan kimia melalui pictogram GHS. Pictogram tersebut disesuaikan dengan standart yang juga ditetapkan pada peraturan perindustrian dan Purple Book oleh United Nations (UN). Setelah dilakukan analisis penerapan pictogram pada Pabrik-2 hingga Pabrik-6, diperoleh data sebagai berikut:

a. Penerapan pada Pabrik-2 telah berjalan $60 \%$

b. Penerapan pada Pabrik-3 telah berjalan $72 \%$

c. Penerapan pada Pabrik-4 telah berjalan $62,5 \%$

d.Penerapan pada Pabrik-5 telah berjalan $81,25 \%$

Berdasarkan data tersebut dapat diketahui bahwa pada masing-masing pabrik terkait penerapan pictogram sebagian besar sudah berjalan dengan baik, kekurangan yang terjadi diantaranya seperti kurang update dengan ketentuan sifat bahan kimia yang terbaru dan/atau wadah bahan kimia yang belum terpasang pictogram dengan jelas yaitu masih berupa tabel NFPA yang tertempel.

\section{Kompatibilitas Bahan Kimia}

Chemical compatibility atau kekompatibilitasan bahan kimia merupakan ukuran yang digunakan dalam melihat stabilitas bahan kimia apabila dicampur dengan bahan kimia yang lain dimana dengan sifat yang berbeda. Pengkategorian yang akan dilakukan melalui metode ini nantinya adalah melalui pengamatan yang dilakukan dengan melihat dua zat jika mengalami reaksi makan zat tersebut dianggap tidak sesuai dan tidak cocok apabila diletakkan dalam satu wadah atau satu tempat secara bersmaan.

Penerapan kompatibilitas kimia yang telah dilakukan di PT Pupuk Kaltim diterapkan dalam penyimpanan bahan kimia di setiap unit area produksi di masing-masing shelter pabrik. Hasil kompatibilitas tersebut sebagai berikut:

Tabel.2 Kompatibilitas chemical shelter di area produksi PT Pupuk Kaltim

\begin{tabular}{|c|c|}
\hline Chemical shelter & Kompatibilitas \\
\hline Phospat dan amine & Kompatibel \\
\hline $\begin{array}{l}\text { Phospat } \\
\text { hydrazine }\end{array}$ & Kompatibel \\
\hline $\begin{array}{l}\text { Phospat, amoniak } \\
\text { cair dan hydrazine }\end{array}$ & Kompatibel \\
\hline $\begin{array}{l}\text { Sodium nitrit dan } \\
\text { biocide }\end{array}$ & Tidak kompatibel \\
\hline Biocide dan nitrite & Tidak kompatibel \\
\hline
\end{tabular}

Sumber: data primer

Hasil tersebut merupakan sebagian besar bahan kimia yang disimpan di area produksi PT Pupuk Kaltim, mulai Pabrik-2 hingga Pabrik-5 sebagian besar yang disimpan adalah bahan-bahan kimia yang ditampilkan pada tabel.2. Berdasarkan tabel.2 tersebut dapat diketahui bahwa belum semua tempat penyimpanan bahan kimia telah aman, masih terdapat bagian chemical shelter yang bahan kimia didalamnya harus dipisahkan. Dalam menentukan kompatibilitas antar bahan kimia tersebut menggunakan klasifikasi menurut Chemical Mixing Compatibility Chart (EPA600/2-80-076/April 1980) beserta hasil reaksi yang akan terjadi. 


\section{Pembahasan}

Dalam melakukan upaya pencegahan kecelakaa kerja akibat penggunaan bahan kimia, diperlukan beberapa aspek dalam menjalankan chemical handling, hal mendasar atau step awal yang perlu dilakukan mengenai chemical handling adalah mengetahui beberapa istilah yang berhubungan dengan chemical handling secara aman itu sendiri, seperti hazard yang merupakan segala sesuatu yang menimbulkan bahaya maupun cedera, seperti contoh seseorang yang bekerja dengan bahan kimia berbahaya atau proses yang menimbulkan risiko. Selain itu risiko sebagai peluang bahwa seorang pekerja tersebut akan dirugikan oleh bahaya yang diakibatkan dari suatu bahan kimia. Kemudian likelihood sebagai ukuran seberapa besar kemungkinan kecelakaan atau kesehatan akann terjadi. Ketikia seseorang bekerja dan melakukan penanganan bahan kimia, disana kemungkinan kecelakaan maupun gangguan kesehatan akan terjadi. Kemudian MSDS yang merupakan dokumen yang harus diberikan kepada pekerja dengan semua informasi mengenai kemungkinan bahayanya. Hal tersebut sangat membantu dalam melakukan safe handling dan emergency response terhadap bahan kimia jika terjadi sebuah insiden ${ }^{12}$. Selain itu masih ada label yaitu juga sebagai informasi bahan kimia beserta identitas nya, kemudian ada $C A S$ Number yaitu sebagai nomer dalam mengidentifikasi untuk setiap bahan kimia. Kemudian ada Occupational Exposure Limit Value (OELV) yaitu sebagai nilai ambang batas dari konsentrasi bahan kimia yang dirasa tidak akan menimbulkan bahaya pada pekerja yang melakukan pekerjaan, dan yang terakhir adalah inventaris bahan kimia dimana dilakukannya pengurutan atau listing dari semua bahan kimia yang dilakukan dan digunakan di perusahaan tersebut ${ }^{3}$.

Langkah berikutnya adalah dengan mengetahui nama-nama beserta tipe maupun sifat dari bahan kimia yang ada di tempat kerja. pada proses observasi yang telah dilakukan di area produksi PT Pupuk Kaltim, telah terkumpul sekitar 33 nama bahan kimia dengan sifat dan tipe yang beragam. Langkah berikutnya adalah menunjukkan bagaimana cara dalam menerapkan penanganan bahan kimia atau chemical handling yang tepat dan sesuai pada tempat kerja dengan anjuran dalam peraturan. Pada observasi kali ini peraturan yang akan digunakan adalah menurut Permen Industri Nomor 23 tahun 2013. Sehingga setiap langkah dan tahapan penanganan bahan kimia akan disesuaikan sebagai yang telah diatur dalam peraturan tersebut ${ }^{6}$.

Berdasarkan pegamatan yang dilakukan pada praktek keselamatan kerja penerapan chemical handling di area produksi PT Pupuk Kaltim dapat disimpulkan sudah baik, meskipun masih perlu adanya pembenahan di bagian-bagin tertentu. Hal mendasar pada penerapan chemical handling yang pertama adalah dari ketersediaan buku manual informasi bahan kimia atau yang biasanya disebut dengan MSDS atau LDKB. Pada PT Pupuk Kaltim ketersediaan buku informasi tersebut telah dilakukan dan perusahaan memiliki buku MSDS yang dikeluarkan sendiri khusus untuk bahan kimia yang hanya digunakan di perusahaan ${ }^{9}$. Informasi tersebut tentu mengacu dan mengadopsi dari MSDS supplier utama bahan kimia. Konten yang terdapat pada buku MSDS perusahaan juga telah disesuaikan dengan format untuk konten berdasarkan Permen Industri Nomor 23 tahun 2013. Namun beberapa nama bahan kimia hasil observasi belum ditemukan informasi di MSDS keluaran terakhir yang dimiliki perusahaan, sehingga harus dilakukan upaya pembuatan MSDS bahan kimia yang mengacu pada MSDS supplier bahan kimia ${ }^{11}$.

Langkah chemical handling berikutnya adalah dari aspek pentingnya sebuah simbol pictogram bahan kimia. Simbol pictogram bahan kimia yang dimaksudkan adalah berupa stiker atau yang lainnya yang dapat menempel dengan baik pada kemasan bahan kimia atau 
pada chemical storage dan pada kendaraan pengangkut bahan kimia. Simbol pictogram tersebut juga harus disesuaikan dengan karakteristik bahan yang dikemasnya atau diwadahinya. Simbol juga harus terbuat dari bahan yang tahan terhadap air, goresan, ataupun bahan kimia yang mungkin mengenainya (misalnya bahan plastic, kertas, atau plat logam). Beberapa jenis simbol pictogram menurut GHS (Globally Harmonized Sistem) diantaranya seperti pada tabel berikut ini ${ }^{7}$ :

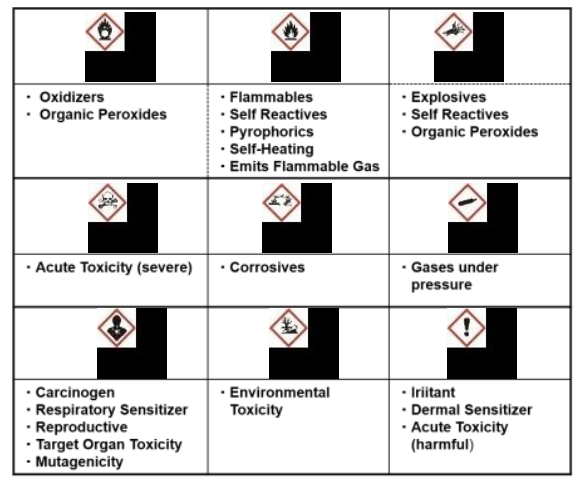

Gambar 1. Pictogram GHS

Sumber: data sekunder

Sifat-sifat bahan kimia tersebut merupakan simbol pictogram standart dan kriteria yang mengacu pada GHS. Standart pictogram tersebut diatur menurut UN Recommendation dimana elemen grfis seperti pola latar belakang, warna, grafis lainnya dimaksudkan untuk menyampaikan informasi spesifik dari bahan kimia yang tersimpan.

Berdasarkan hasil observasi yang dilakukan di PT Pupuk Kaltim, sebuah bahan kimia yang sebagian besar dilakukan penyimpanan pada tangki-tangki khusus, sehingga informasi dari isi pada tangka tersebut juga diperlukan. Pada observasi di Pabrik-2 terdapat sekitar 20 buah chemical storage yang digunakan untuk menyimpan bahan kimia, dan sekitar $60 \%$ nya kesesuaian dan tata letak pemasangan simbol pictogram telah benar dan sesuai, kekurangan yang terjadi pada Pabrik-2 pada pemasangan pictogram adalah masih terdapat pictogram yang belum dilakukan update menurut sifat bahan kimia yang terbaru. Sifat bahan kimia yang ter update adalah menggunaan informasi dari EPA (Environmetal Protection Agency) dan situs pubchemdocs.ncbi.nlm.nih.gov/. dimana kedua sumber tersebut merupakan sumber yang dirasa paling update untuk masalah sifat bahan kimia. Sementara hasil untuk obsevasi pada Pabrik-3 memperlihatkan bahwa sekitar $72 \%$ penerapan untuk pemberian simbol pictogram telah berjalan, hal ini sudah tergolong baik. Penerapan di Pabrik-3 yang sebagian besar belum terlaksana dikarenakan belum terpasangnya simbol pictogram tersebut dengan baik pada setiap tempat penyimpanan bahan kimia, sehingga yang terlihat adalah hanya tangki-tangki atau drum kosong tanpa label, dimana yang mengetahui isi yang ada di dalam tangka bahan kimia tersebut hanya lah operator yang bertugas, sementara jika terdapat orang baru yang memasuki area tersebut akan sangat fatal apabila melakukan tindakan atau penanganan yang salah terkait bahan kimia yang terdapat di dalamnya. Sehingga tindakan tersebut perlu dilakukan pembenahan. Kemudian penerapan di Pabrik-4 telah berjalan 62,5\%, pada Pabrik4 ini sisa kekurangan yang belum diterapkan adalah karena masih menggunakan angka NFPA sebagai informasi pada tempat penyimpanan bahan kimia, namun ada juga yang memberikan informasi tersebut juga ditambahkan dengan symbol pictogram, juga masih ada beberapa drum bahan kimia dimana dengan simbol pictogram yang sudah usang atau tidak dapat terlihat dengan jelas. Kemudian untuk penerapan simbol pictogram di Pabrik-5 telah berjalan 81,5\%, disini penerapan mengenai simbol telah berjalan lebih baik diantara pabrik-pabrik sebelumnya, karena memang pada Pabrik-5 ini merupakan pabrik yang baru saja berdiri yaitu sekitar tahun 2012 sehingga segala operasional pendukung pabrik masih dalam keadaan bagus, masalah kurangnya ketercapainnya adalah masih ditemukan beberapa tempat 
penyimpanan bahan kimia yang kurang sesuai dengan standart dari United Nation untuk kriteria sifat bahan kimia, sehingga simbolsimbol juga masih ada beberapa yang belum dilakukan update ulang.

\section{Kompatibilitas dan Tata Letak Penyimpanan Bahan Kimia}

Berdasarkan temporary chemical shelter yang ada di PT Pupuk Kaltim, bahan-bahan kimia yang telah dilakukan pendataan sebelumnya dilakukan identifikasi berdasarkan sifat masing-masing bahan, hal tersebut sangat perlu dilakukan untuk menentukan tata letak penyimpanan bahan kimia, karena setiap bahan kimia belum tentu kompatibel atau cocok ditempatkan dalam satu area tertentu dengan bahan kimia yang lain. Penyimpanan bahan kimia tanpa memperhatikan dan mempertimbangkan kompatibilitasnya dapat menimbulkan risiko terjadinya reaksi yang berbahaya, terutama jika terjadi reaksi hingga menimbulkan pecahnya kemasan. Maka dari itu bahan kimia yang telah tersimpan dalam temporary chemical shelter di PT Pupuk Kaltim akan ditentukan kompatibilitasnya melalui metode menurut Municipal Environmental Research Laboratory Office of Research and Development U.S Environmental Protection Agency (EPA) yaitu berupa metode untuk menentukan kompatibilitas dari kombinasi bahan kimia ${ }^{8}$. Metode perhitungan ini terdiri dari tiga kolom diantaranya kolom pertama berisikan chemical names secara alphabetic, lalu kolom kedua berisi sinonim dari bahan kimia atau common names of chemical substances, kolom ketiga berisi kode RGN (Reactivity Group Number) yang mana adalah karakteristik atau sifat bahan kimia beserta kode nomer sifat bahan kimia tersebut, yang kemudian setelah mengetahui sifat bahan kimia dari RGN, langkah berikutnya adalah menentukan kemungkian reaksi atau consequence yang terjadi dari masing-masing bahan kimia apabila bertemu dengan sifat bahan kimia yang lain. Kemungkinan reaksi atau consequence tersebut digolongkan kedalan delapan kelas diantaranya (F) Fire, (G) Innoucuous and Non-Flammable Gas Generation, (H) Heat Generation, (GT) Toxic Gas Generation, (GF) Flammable Gas Generation, (E) Explosion, (P) Violent Polymerization, (S) Solubilization of Toxic Substance, (U) Maybe Hazardous. Setelah itu RGN yang sudah diperoleh dimasukkan ke dalam tabel klasifikasi menurut Chemical Mixing Compatibility chart (EPA600/2-80-076/April 1980) hingga akhirnya diperoleh hasil reaksi ${ }^{8}$.

Impelemtasi di PT Pupuk Kaltim terlihat pada Tabel 2 yaitu berupa hasil keseluruhan yang dilakukan di area produksi di PT Pupuk Kaltim. Sementara jika dilakukan penjabaran maka di Pabrik-2 terdapat empat tempat sebagai chemical shelter dimana di area amoniak terdapat shelter untuk phospat dan amine, jika dijabarkan phospat memiliki sifat sebagai garam stabil, sementara amine dengan sifat aromatic, aliphatic dengan kereaktifan zat yang stabil, sehingga apabila kedua bahan ditempatkan dalam shelter yang sama tidak menimbulkan reaksi berbahaya dan kedua bahan tersebut kompatibel. Sementara untuk unit utility di Pabrik-2 terdapat dua shelter yaitu di unit utility area WHB dan area cooling water, area WHB terdapat shelter untuk phospat dan hydrazine, jika dijabarkan phospat dengan sifat garam stabil dan hydrazine dengan sifat azo compounds, diazo compounds and hydrazine ${ }^{10}$ yang keduanya jika dilakukan penyimpanan pada lokasi yang sama tidak menimbulkan reaksi dan kompatibel. Untuk area cooling water terdapat shelter untuk sodium nitrit dengan sifat oxidizing aget and strong, dan biocide dengan sifat hydrocarbon, aliphatic, saturated. Jika diuraikan kedua bahan tersebut menghasilkan consequence berupa (HF) Heat and Fire Generation, sehingga kedua bahan tersebut tidak kompatibel apabila ditempatkan dalam lokasi yang sama karena dapat memicu terjadinya panas dan kebakaran. 
Selanjutnya kompatibilitas bahan kimia di Pabrik-3. Unit amoniak Pabrik-3 menyimpan hydrazine dan antifoam (ucon) yang ditempatkan dalam lokasi yang berdekatan, namun hasil tersebut tidak dapat teridentifikasi kompatibilitasnya, namun jika melihat sifatnya hydrazine memiliki sifat azo compound dan diazo compounds hydrazine sementara antifoam (ucon) merupakan bahan kimia campuran yang juga tidak dapat teridentifikasi. Sehingga kekurangan pada sifat bahan kimia ini yang kemudian peneliti tidak dapat memberikan deskripsi secara mendetail. Beralih ke unit utility Pabrik-3 area WHB menyimpan phospat, amoniak cair dan hydrazine $^{10}$, jika diuraikan phospat memiliki sifat garam stabil, hydrazine dengan sifat azo compound, diazo compound hydrazine, dan amoniak cair dengan sifat caustic dimana dengan sifat yang mudah larut dalam air, ketiga bahan tersebut tidak menimbulkan reaksi berbahaya jika ditempatkan pada lokasi yang sama sehingga shelter utility area WHB dikategorikan kompatibel. Selanjutnya unit utility area cooling water Pabrik-3 terdapat shelter untuk biocide dan sodium nitrite, jika diuraikan sodium nitrite memiliki sifat oxidizing agent and strong sementara biocide memiliki sifat hydrocarbon, aliphatic, saturated. Apabila kedua bahan kimia di tempatkan dalam lokasi yang sama consequence yang akan terjadi adalah (HF) Heat and Fire Generation, sehingga chemical shelter unit utility area cooling water tidak kompatibel karena dapat memicu terjadinya panas dan kebakaran yang akan membahayakan lingkungan sekitar shelter tersebut.

Chemical shelter berikutnya di Pabrik-4 hanya terdapat di unit utility saja yaitu area cooling water dimana menyimpan biocide dan nitrite, jika di jabarkan biocide dengan sifat hydrocarbon, aliphatic, saturated dan sodium nitrite dengan sifat oxidizing agent strong ${ }^{10}$, dimana keduanya akan menimbulkan (HF) Heat and Fire Generation, sehingga bahan kimia yang ada di dalamya harus segera dipisahkan karena tidak kompatibel yang memicu terjadinya panas dan kebakaran.

Kemudian evaluasi berikutnya di Pabrik-5, pada penerapan chemical handling untuk kompatibilitas chemical shelter disini belum terlaksana, karena sebagian besar bahan kimia di Pabrik-5 ini disimpan berdekatan dengan area loading bahan kimia, hal tersebut dengan alasan untuk mempermudah jika terdapat bahan kimia yang harus melakukan loading secara manual, selain itu tempat penyimpanan yang ada di Pabrik-5 juga belum memiliki penyimpanan seperti yang diatur dalam peraturan yaitu dari segi bangunan yang harus mampu terhindar dari sinar matahari, hujan dan bahaya fisik lainnya. Sehingga di Pabrik-5 diperlukan pembangunan chemical shelter yang bersifat temporer atau menetap untuk bahan kimia yang digunakan di Pabrik-5.

Evaluasi Pabrik-6, disini area produksi yang digunakan dan masih aktif hanya unit utility, dimana juga telah memiliki shelter sebagai tempat menyimpan bahan kimia, shelter tersebut berisi hydrazine dan phospat, hydrazine memiliki sifat azo diazo compounds and hydrazine, sementara phospat adalah garam stabil ${ }^{10}$, sehingga kedua sifat terebut jika dilihat pada tabel chemical mixing compatibility chart dari EPA tidak memiliki reaksi berbahaya apapun yang kemungkinan terjadi, sehingga kedua bahan kimia tersebut kompatibel untuk ditempatkan dalam satu area yang sama.

\section{Kesimpulan}

Dari penelitian yang dilakukan pada PT Pupuk Kaltim mengenai evaluasi dari penerapan chemical handling, penerapan yang telah dilakukan dapat disimpulkan bahwa sudah berjalan dengan baik seperti klasifikasi bahan kimia telah dilakukan menurut wujud, bahaya dan sifat. Kemudian ketersediaan buku informasi bahan kimia atau Lembar Data 
Keselamatan Bahan (LDKB) juga telah terpenuhi dan distribusi buku LDKB tersebut juga telah menyeluruh ke semua area proses produksi PT Pupuk Kaltim. Namun meskipun demikian masih terdapat beberapa kekurangan pada penerapan simbol pictogram GHS yang masih belum sesuai dengan update sifat bahan kimia terbaru dan juga masih ada yang bahkan tidak terpasang simbol pictogram GHS. Serta ketersediaan rumah kimia sebagai temporary chemical shelter masih ditemukan bahan yang disimpan tidak sesuai atau tidak kompatibel antar bahan kimia sehingga berpeluang mengganggu keselamatan dan kesehatan kerja.

\section{Saran}

1. Sebagai upaya penanganan terhadap potensi bahaya, sebaiknya perlu dilakukan upaya sebagai berikut:

a. Perlu dilakukannya update ulang mengenai MSDS perusahaan yaitu pada nama-nama bahan kimia yang belum tercantum namun digunakan dalam proses produksi.

b. Bahan kimia yang digunakan di area produksi PT Pupuk Kaltim yang tidak kompatibel sebaiknya tidak disimpan dalam satu chemical shelter dan sebaiknya dilakukan pembuatan shelter tambahan.

c. Update pictogram di setiap tempat penyimpanan bahan kimia perlu dilakukan peninjauan ulang.

d. Informasi mengenai sifat bahan kimia dan kompatibilitas bahan kimia perlu dibuatkan tabel kompatibilitas bahan kimia dan ditempel di setiap chemical shelter, sebagai informasi bahan kimia yang disimpan di tempat tersebut, sehingga baik operator maupun orang baru dapat mengetahui dan terbaca dengan jelas.

e. Setiap bahan kimia yang masih ditempatkan di dekat area loading chemical memerlukan tempat penyimpanan khusus (chemical shelter).

\section{Daftar Pustaka}

1. PT Katindo Megah Utama. 2018. Modul Pembinaan Calon Ahli K3 Umum. Jakarta: Author.

2. Center For Chemical Process Safety. 2004. Process Safety Beacon Bhopal-A Tragic Event. New York: An AIChE Industry Technology Alliance.

3. Health And Safety Authority. 2017. Your Steps to Chemical Safety A Guide For Small Business. Ireland: Author.

4. Rahmatullah, M., Naiem, M.F., Muis, M. 2013. Keamanan Bahan Kimia Berbahaya Pada Karyawan Percetakan Kota Makassar. Diakses dari repository.unhas.ac.id/

5. PT Pupuk Kalimantan Timur. 2018. Panduan Kerja Praktik PT Pupuk Kalimantan Timur. Bontang: Author.

6. Republik Indonesia, 2003. Peraturan Menteri Industri Nomor 23 Tahun 2003 Tentang Perubahan Sistem Harmonisasi Global Klasifikasi Dan Label Pada Bahan Kimia.

7. United Nation. 2003. Globally Harmonized Sistem of Classification And Labelling Of Chemical (GHS). New York And Geneva: United Nations.

8. United State Environmental Protection Agency. 1980. A Method For Determining The Compatibility Of Hazardous Waste. Cincinnati, Ohio: Municipal Environment Research Laboratory Office Of Research And Development.

9. PT Pupuk Kalimantan Timur. 2016. LDKB Lembar Data Keselamatan Bahan. Bontang: Author. 
10. National Institue of Health (NIH). 2018. Pubchem. Diakses dari pubchemdocs.ncbi.nlm.gov/

11. PT Pupuk Kalimantan Timur. 2010. Panduan Teknis Penerapan GHS PT Pupuk Kalimantan Timur. Bontang: Author.

12. America Institute of Chemical Engineers. 2016. Indtroduction to Process Safety for Undergraduatesand Engineers. Canada: John Wiley \& Sons, Inc., Hoboken, New Jersey. 